\title{
Cooking Loss of Major Onion Antioxidants and the Comparison of Onion Soups Prepared in Different Ways
}

\author{
Makiko Takenaka $^{1,2}$, Kazuko Nanayama ${ }^{1}$, Isamu OhnukI ${ }^{3}$, Masanobu Udagawa ${ }^{3}$, Eisuke Sanada ${ }^{3}$ and \\ Seiichiro IsoBE ${ }^{1}$ \\ ${ }^{I}$ National Food Research Institute, 2-1-12 Kannondai, Tsukuba, Ibaraki 305-8642, Japan \\ ${ }^{2}$ Ochanomizu University, 2-1-1 Otsuka, Bunkyo-ku, Tokyo 112-8610, Japan \\ ${ }^{3}$ Association des Disciples d'Auguste Escoffier du Japon, 5-13-11 Shiba, Minato-ku, Tokyo 108-0014, Japan
}

Received February 24, 2004; Accepted August 17, 2004

\begin{abstract}
After sautéing or frying onions as a first procedure in making onion soup, major onion antioxidants (quercetin $4^{\prime}$-glucoside and quercetin 3,4'-diglucoside) remained mostly intact. In the onion soup prepared with sautéed onions, the quantity of flavonoids remained high, but in the onion soup prepared with fried onions, a part of them was changed during cooking. The heating stability of these flavonoids was investigated through simple boiling and oven heating of these compounds. Major onion antioxidants were quite stable in a simple cooking model of boiling and oven heating at $100^{\circ} \mathrm{C}$ but considerably degraded in that of oven heating at $200^{\circ} \mathrm{C}$. DPPH (1,1-diphenyl-2-picrylhydrazyl) radical scavenging activity of sautéed onions was similar to that of raw onions, and fried onions exhibited much higher activity based on equivalent amounts of raw onion. Fried onions had much higher browning degree than sautéed onions, and the browning substance was found to contribute to the radical scavenging activity. The onion soup prepared with sautéed onions had DPPH radical scavenging activity similar to plain sautéed onions, but the onion soup prepared with fried onions had much lower activity than fried onions alone.
\end{abstract}

Keywords: onion, Allium cepa, onion soup, antioxidants, quercetin

\section{Introduction}

The onion (Allium cepa) is a vegetable rich in flavonoids (Tsushida and Suzuki, 1996) that are known to play an important role as antioxidants in reducing the risk of degenerative diseases of aging, such as cardiovascular disease and various cancers (Ames et al., 1993). Organosulfur compounds such as sulfides and isochiocyanates in Allium vegetables also have been found to have beneficial effects regarding antioxidant property against several diseases including cancer (Bianchini and Vainio, 2001). In many countries, onions are often eaten after being cooked in a wide variety of ways. Recently, some results on functional ingredients of cooked vegetables have been reported (Hirota et al., 1998; Ioku et al., 2001; Makris and Rossiter, 2001). Most of these tests were made under simple cooking conditions, and there are few examples which investigated the changes of functional ingredients during practical cooking considering the complex handling or the influence of various additives like oils or seasonings.

Onion soup is a typical French dish eaten in many countries. We investigated major onion antioxidants in onion soups prepared both with sautéed onions and fried onions. Using sautéed onions is more traditional and requires a refined technique and long cooking times to create an appetizing brown color with proper finishing conditions. Fried onions are often used as a simple, quick substitute. To ensure constant, high quality, both types of onion soup

E-mail: tknk1221@nfri.affrc.go.jp were prepared by a professional chef of the Association des Disciples d' Auguste Escoffier du Japon, an authoritative association of French chefs. In this study, we evaluated how well flavonoids of onions withstood cooking in onion soups prepared in different ways and how radical scavenging activity of onions shifted during the preparation of onion soup.

\section{Materials and Methods}

Materials Onions (Momiji 3 gou) were obtained from Tokushima Prefecture in Japan. Butter (Morinaga milk industry Co., Ltd., Japan), salad oil (Ajinomoto Co., Inc., Japan), beef bouillon powder (Ajinomoto Co., Inc.), and tap water were used for the additional components of onion soup.

Chemicals Quercetin 4'-glucoside (Q4'G), quercetin 3,4'-diglucoside $\left(\mathrm{Q} 3,4^{\prime} \mathrm{G}\right)$, and isorhamnetin $4^{\prime}$-glucoside $\left(\mathrm{I} 4^{\prime} \mathrm{G}\right)$ were separated from the onions and purified by preparative HPLC. Other chemicals were analytical grade.

Onion soup recipes Sautéed type: Sliced onions (15 $\mathrm{kg}$ ) were sautéed in an aluminum pan with $120 \mathrm{~g}$ butter for a total of 2.75 hours. Onion samples sautéed for 1 and 2 hour(s) (early and middle stages) were saved for analyses. Nine hundred milliliters of beef bouillon solution $(1.1 \%$, powder/water, w/w) was added to $150 \mathrm{~g}$ sautéed onions, then heated until reduced to $900 \mathrm{ml}$ total volume. Fried type: Four hundred grams of sliced onions was fried in salad oil for $10 \mathrm{~min}$ at $120^{\circ} \mathrm{C}$. In the same way, $1080 \mathrm{ml}$ beef bouillon was added to $90 \mathrm{~g}$ of the fried onions. These 
were heated and reduced to $900 \mathrm{ml}$. Both onion soups were prepared in an aluminum pan heated by a gas cooker. In the final process, excess oil and surface scum were removed from the surface of the soup.

Extraction of flavonoids Each sample was freezedried. The samples, which corresponded to $10 \mathrm{~g}$ of raw materials, were homogenized in $10 \mathrm{ml}$ of $80 \% \mathrm{MeOH}$ and centrifuged. The precipitates were washed with $80 \% \mathrm{MeOH}$ two more times. Each total supernatant was adjusted to 50 ml with $80 \% \mathrm{MeOH}$ and filtered through a cartridge filter ( $0.45 \mu \mathrm{m}$ pore size, Nacalai Tesque, Japan). This solution was used for HPLC analysis, measurement of DPPH radical scavenging activity, and measurement of browning degree.

HPLC analysis HPLC analysis was conducted with a HPLC system (Jasco, Japan) using the $\phi 4.6 \times 150 \mathrm{~mm}$, COSMOSIL $5 \mathrm{C}_{18}$-MS column (Nacalai Tesque, Japan). The samples were eluted with the linear gradient of 10 to $100 \%$ acetonitrile in $10 \mathrm{mM}$ phosphoric acid solution at a flow rate of $1.0 \mathrm{ml} / \mathrm{min}$. The detector was set at $280 \mathrm{~nm}$. Q4' $\mathrm{G}$, $\mathrm{Q} 3,4^{\prime} \mathrm{G}$, quercetin, and $\left(\mathrm{I}^{\prime} \mathrm{G}\right)$ were quantified.

Reproducing onion soup with fried onions Onion soup with fried onions was prepared with the same composition of materials along with the recipe described above. Sliced onion $(130 \mathrm{~g})$ was fried in salad oil for $10 \mathrm{~min}$ at $120^{\circ} \mathrm{C}$ to $33 \mathrm{~g}$. The fried onion $(20 \mathrm{~g})$ and beef bouillon (1.1\%, powder/water, w/w, $245 \mathrm{ml}$ ) was heated for $13 \mathrm{~min}$. The onion soup was separated to onion and soup parts by decanting without removing oil. The onion part was rinsed with distilled water $(20 \mathrm{ml})$, which was added to the soup part. The soup part was then put in a separating funnel, and oil and water layers (15 and $200 \mathrm{ml}$, respectively) were separated.

Extraction and HPLC measurement of flavonoids in each part of the reproduced onion soup The onion part was freeze-dried and extracted by $80 \% \mathrm{MeOH}$ in the same way as described above. The oil part was extracted by $\mathrm{MeOH}$, and the extract was adjusted to $100 \mathrm{ml}$. The water part was adjusted to $250 \mathrm{ml}$ with distilled water, then 10 $\mathrm{ml}$ was freeze-dried. The dried sample was extracted by $80 \% \mathrm{MeOH}$ and adjusted to $10 \mathrm{ml}$. These extracts were measured to determine the contents of flavonoids by HPLC using the same conditions as described above.

Model boiling One milligram of each of $\mathrm{Q} 4^{\prime} \mathrm{G}$ and $\mathrm{Q} 3,4^{\prime} \mathrm{G}$ was dissolved in $10 \mathrm{ml}$ of water. The solution was put in a glass flask, which was then stoppered and heated for up to $60 \mathrm{~min}$ in a water bath set at $100^{\circ} \mathrm{C}$. One hundred and fifty microliters of portions of the solution were periodically collected during heating. The collected solutions were immediately cooled in ice and used for HPLC measurement.

Model oven heating Five milligrams of each of Q4'G and $3,4^{\prime} \mathrm{G}$ was put into $\phi 1.2 \times 3.5 \mathrm{~cm}$ glass bottles and heated for 30 and $60 \mathrm{~min}$ in a convection oven set to 100 , 120 , and $200^{\circ} \mathrm{C}$. After heating, the sample was dissolved in $\mathrm{MeOH}(1 \mathrm{ml})$ and used for HPLC measurement.

Measurement of DPPH radical scavenging activity This followed Yan's method (Yan et al., 1999) with the $80 \% \mathrm{MeOH}$ extracts.
Measurement of browning degree Browning degree was evaluated as absorbance at $500 \mathrm{~nm}$ of the $80 \% \mathrm{MeOH}$ extract of each sample. The absorbance was measured by a UV-VIS spectrophotometer, UVmini 1240 (Shimadzu, Japan). The optical path length was $1 \mathrm{~cm}$.

\section{Results and Discussion}

The contents of major onion antioxidants Q4'G, Q3,4'G, and $\mathrm{I}^{\prime} \mathrm{G}$ in raw onion, cooked onions, and onion soups prepared in different ways are shown in Fig. 1. Quercetin was not detected in any sample. Most of those flavonoids were retained in the onions after sautéing, frying, and preparing onion soup with sautéed onions. However, more than half of the flavonoids were lost when soup was prepared with fried onions. One possible reason for the decrease of flavonoids in the onion soup made with fried onions was that flavonoids were removed with surface oil during preparation of the soup because fried onions had much more oil than sautéed ones. To investigate this possibility, onion soup with fried onions was reproduced with the same recipe in a laboratory, where the onion, oil, and water parts were separated. The contents of major onion flavonoids corresponding to the total amount of each part in a pot of onion soup are shown in Fig. 2. This result, with the exception of some difference of degree, was consistent with the previous result that used onion soup prepared by a chef with fried onions. In the reproduced onion soup, quite a few flavonoids $(0.4 \%$ of total flavonoids in fried onions) were detected in the oil part, $44 \%$ in the water part, and $16 \%$ in the onion part. Quercetin was not detected in any part. In the onion part, a composition of $\mathrm{Q} 3,4^{\prime} \mathrm{G}, \mathrm{Q} 4^{\prime} \mathrm{G}$, and $\mathrm{I}^{\prime} \mathrm{G}$ was changed from raw and fried onions, and the loss rate of $\mathrm{Q} 3,4^{\prime} \mathrm{G}$ was much higher than that of $\mathrm{Q} 4^{\prime} \mathrm{G}$ and $\mathrm{I}^{\prime} \mathrm{G}$. The result of the reproduction test indicates that major flavonoids in fried onions were partly dissolved in the oil and removed with it, and some part was lost by degradation or aggregation with other components during heating with bouillon.

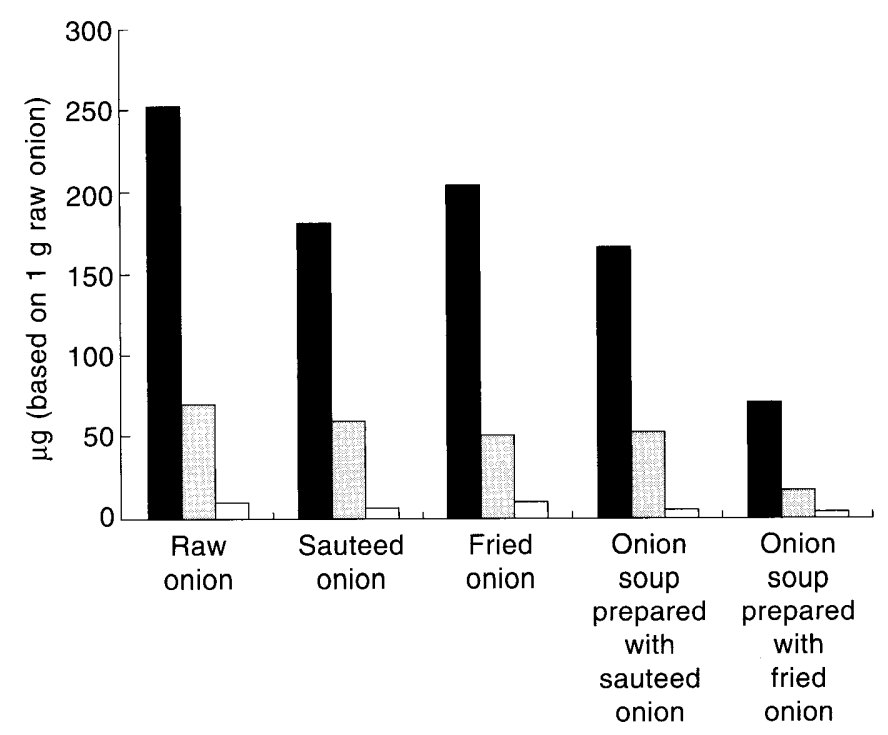

Fig. 1. Amount of major flavonoids in raw onion, cooked onions, and onion soups based on $1 \mathrm{~g}$ of raw onion. $-\mathrm{Q} 3,4^{\prime} \mathrm{G}$; $:$ : Q $4^{\prime} \mathrm{G} ; \square: \mathrm{I} 4^{\prime} \mathrm{G}$. 


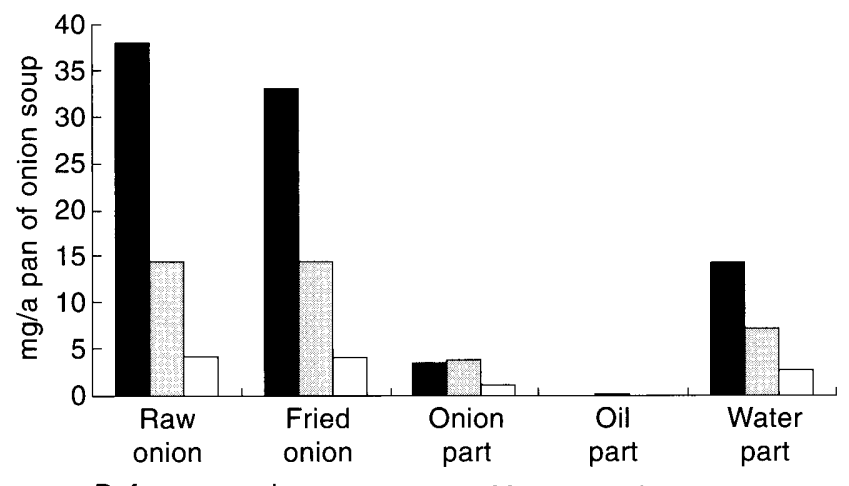

Before preparing soup After preparing soup

Fig. 2. Contents of major onion antioxidants before and after preparing onion soup (reproducing test). $\mathbf{a}:$ Q3, 4'G; $\mathrm{D}$ : Q4'G; $\square \mathrm{I} 4^{\prime} \mathrm{G}$.
In the practical cooking of onions, flavonoids showed different behavior depending on cooking ways. To investigate the influence of heat, some models of cooking used Q4'G and Q3,4'G which are major onion antioxidants. Sautéing and frying are often used as onion cooking methods, and they are classified as dry heating. As a simple model of dry heating, oven heating $\left(100,120\right.$, and $\left.200^{\circ} \mathrm{C}\right)$ was performed. For comparison, boiling $\left(100^{\circ} \mathrm{C}\right)$ was performed as a simple model of wet heating. In the simple cooking model of $\mathrm{Q} 4^{\prime} \mathrm{G}$ and $\mathrm{Q} 3,4^{\prime} \mathrm{G}$, they were quite stable when boiled for $60 \mathrm{~min}$ (Fig. 3, A and B). Similarly, they were stable when heated by oven for $60 \mathrm{~min}$ at $100^{\circ} \mathrm{C}$ (Fig. $3, \mathrm{C}$ and D). At $120^{\circ} \mathrm{C}$ of oven heating, they were degraded to about $90 \%$ in 60 min (Fig. 3, E and F). In the practical

A
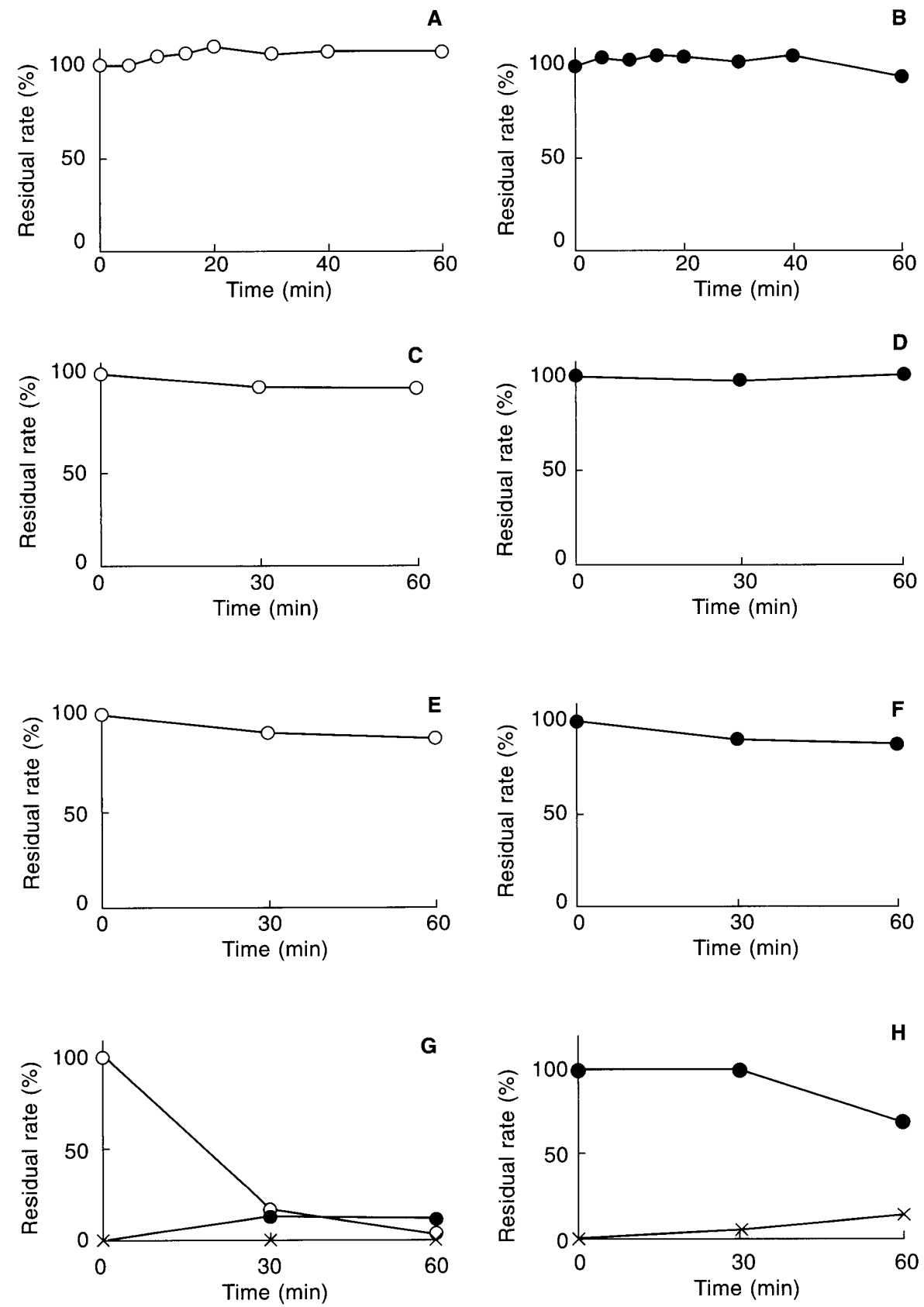

Fig. 3. Residual rates after model cooking of major onion antioxidants. A. Boiling of $\mathrm{Q} 3,4^{\prime} \mathrm{G}, \mathbf{B}$. Boiling of $\mathrm{Q} 4^{\prime} \mathrm{G}$, C. Oven heating $\left(100^{\circ} \mathrm{C}\right)$ of $\mathrm{Q} 3,4^{\prime} \mathrm{G}$, D. Oven heating $\left(100^{\circ} \mathrm{C}\right)$ of $\mathrm{Q}^{\prime} \mathrm{G}$, E. Oven heating $\left(120^{\circ} \mathrm{C}\right)$ of $\mathrm{Q} 3,4^{\prime} \mathrm{G}, \mathbf{F}$. Oven heating $\left(120^{\circ} \mathrm{C}\right)$ of $\mathrm{Q} 4^{\prime} \mathrm{G}$. G. Oven heating $\left(200^{\circ} \mathrm{C}\right)$ of Q3, $4^{\prime} \mathrm{G}, \mathbf{H}$. oven heating $\left(200^{\circ} \mathrm{C}\right)$ of $\mathrm{Q} 4^{\prime} \mathrm{G}$. $\mathrm{O}: \mathrm{Q} 3,4^{\prime} \mathrm{G} ; \bullet: \mathrm{Q} 4^{\prime} \mathrm{G} ; \times$ : $\mathrm{Q}$. 
cooking of onions, about $80 \%$ of total flavonoids was retained after frying at $120^{\circ} \mathrm{C}$ (Fig. 1 and 2). It is quite difficult to measure the temperature during sautéing, but it is assumed that the temperature is around $100^{\circ} \mathrm{C}$ while sautéed foods have enough water in themselves, and as the water content was decreased, the temperature rises to much higher than $100^{\circ} \mathrm{C}$, and it is just like baking when sautéed foods contact a pan. Incidentally, the water contents of raw and sautéed onions estimated from the weight loss by freeze-drying were $90,83,62$, and $49 \%$ (raw, sautéed for 1, 2, and $2.75 \mathrm{~h}$ ). Additionally, sautéing involves the handling of stirring, so it is thought that the temperature during sautéing is constantly changing and rising overall. Consistently, $25 \%$ of total flavonoids was degraded in sautéing onion (Fig. 1). In the simple dry heating at $200^{\circ} \mathrm{C}$, $\mathrm{Q} 3,4^{\prime} \mathrm{G}$ was considerably degraded, to 16 and $3 \%$ in 30 and $60 \mathrm{~min}$, simultaneously, small amounts of $\mathrm{Q}^{\prime} \mathrm{G}$ and quercetin were detected (Fig. 3, G). Q4'G was degraded to $68 \%$ by oven heating at $200^{\circ} \mathrm{C}$ in $60 \mathrm{~min}$, and a small amount of quercetin was detected (Fig. 3, H). In the cooking model of dry heating, Q3,4'G tended to have lower heating stability than $\mathrm{Q} 4^{\prime} \mathrm{G}$, and this tendency was found in sauteed and fried onions. These results indicate that $\mathrm{Q} 4^{\prime} \mathrm{G}$ and Q3, $4^{\prime} \mathrm{G}$ are stable in common cooking because the temperature of foods during cooking must not exceed $100^{\circ} \mathrm{C}$ unless water is completely lost. $\mathrm{Q}^{\prime} \mathrm{G}$ and $\mathrm{Q} 3,4^{\prime} \mathrm{G}$ were stable in simple heating at $100^{\circ} \mathrm{C}$ under both wet and dry conditions. In dry heating at around $200^{\circ} \mathrm{C}$, such as baking or frying, those compounds may be degraded only around the food surface. From these results, it is indicated that in the practical cooking, quercetin glycosides are relatively resistant to heat itself, and their loss from material to final product may be due to coexisting substances or handling.

The DPPH radical scavenging activity of cooked onions is shown in Fig. 4. Sautéing tended to increase the activity gradually, but the activity was a little lower than for raw onions. After frying, the activity increased to approximately twice that of raw onions. Brown substances, such as Maillard reaction products are known to have higher antioxidant activity (Bressa et al., 1996; Friedman et al., 1996). When onions were heated, a brown product developed, which may have higher antioxidant activity. It was reported that the main browned compounds of heated onion juice are a kind of melanoidin and have lower molecular weight compared with model melanoidin prepared with glycine and glucose (Tamaki and Ukai, 2003; Tamaki et al., 1996), and that raising of the temperature enhanced the browning reaction (Mizoi et al., 1992). As shown in Fig. 1, major onion flavonoids were retained by 75 and $79 \%$ after sautéing and frying, respectively. Considering this result, in Fig. 4, 0.75 and 0.79 of total activity of sautéed and fried onions were from flavonoids, and the remaining 0.19 and 1.05 were probably from a browning substance, i.e., the contribution ratio of flavonoids and browning substance to DPPH radical scavenging activity is estimated at 80:20 and 43:57 in sautéed and fried onions, respectively. Consistently, the fried onions had a much higher degree of browning compared to sautéed onions (Fig. 5). This may

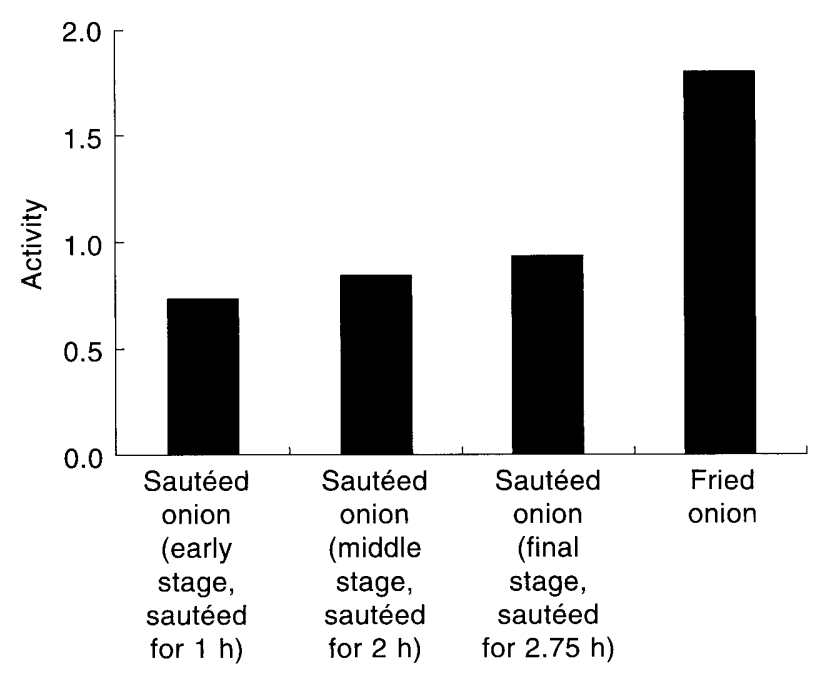

Fig. 4. DPPH radical scavenging activity of sautéed and fried onions based on $1 \mathrm{~g}$ of raw onion (the activity for raw onion $=1$ ).

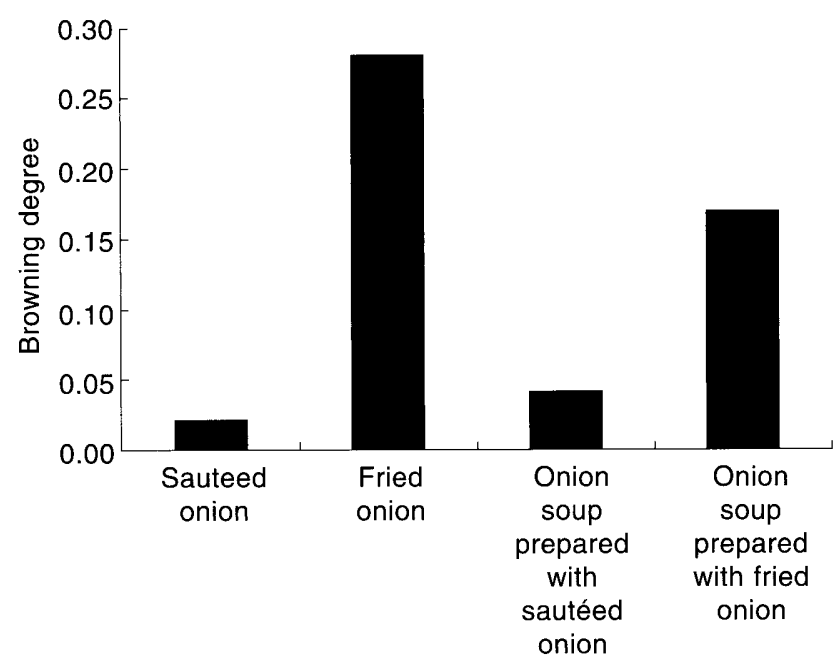

Fig. 5. Browning degree of $80 \% \mathrm{MeOH}$ extract of cooked onions and onion soups.

be related to fried onions being uniformly heated at higher temperature than sauteed onions from the early stage of heating, and the reaction rate of the components relating to browning in fried onions being faster than in sautéed onions.

The antioxidant activity of sautéed onions was retained in the onion soup at a ratio of $85 \%$, but for fried onions, the ratio was only $35 \%$ (Fig. 6). While fried onions had much higher antioxidant activity than raw onions, which came from the browning substance, they lost much activity by losing flavonoids during soup preparation.

\section{Conclusions}

The major onion antioxidants themselves were quite stable in simple cooking. They were retained well in simple sautéing or frying. DPPH radical scavenging activity rose with the browning degree of the cooked onion sample. The onion antioxidants were retained well in onion soup prepared with sautéed onions. The onion antioxidants and the DPPH radical scavenging activity significantly 


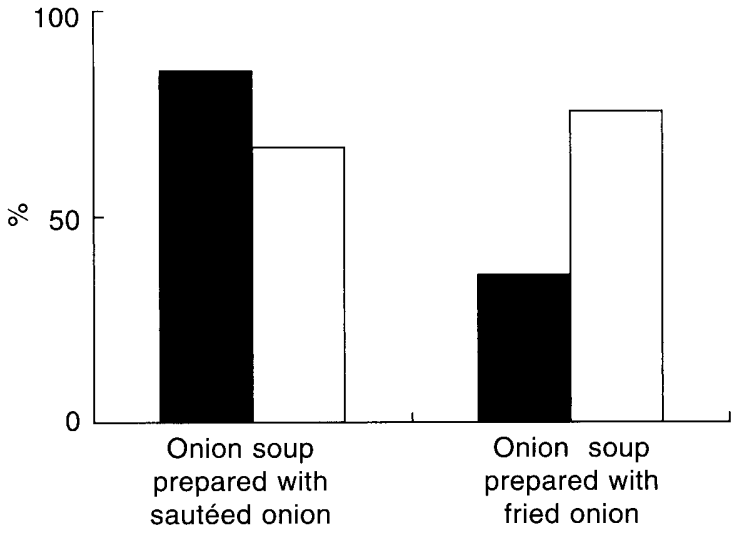

Fig. 6. Ratio of DPPH radical scavenging activities (onion soup/cooked onion, onion soup/raw onion, based on equivalent amounts of onion). onion soup/cooked onion; $\square$ : onion soup/raw onion.

decreased during preparing onion soup with fried onions. We should thus select the food processing method not only for taste but also for how well functional ingredients are retained.

Acknowledgement This study was supported in part by a grant from the Japanese Ministry of Agriculture, Forestry and Fisheries (MAFF) Food Research Project "Integrated Research on Safety and Physiological Function of Food".

\section{References}

Ames, B.M., Shigena, M.K. and Hagen, T.M. (1993). Oxidants, antioxidants and the degenerative diseases of aging. Proc. Natl. Acad. Sci. U.S.A, 90, 7915-7922.
Bianchini, F. and Vainio, H. (2001). Allium vegetables and organosulfur compounds: Do they help prevent cancer? Environ. Health Perspect., 109, 893-902.

Bressa, F., Tesson, N., Rosa, M.D., Sensidoni, A. and Tubaro, F. (1996). Antioxidant effect of Maillard reaction products: Application to a butter cookie of a competition kinetics analysis. J. Agric. Food Chem., 44, 692-695.

Friedman, M. (1996). Food browning and its prevention: an overview. J. Agric. Food Chem., 44, 631-695.

Hirota, S., Shimoda, T. and Takahama, U. (1998). Tissue and spatial distribution of flavonol and peroxidase in onion bulbs and stability of flavonol glucosides during boiling of the scales. J. Agric. Food Chem., 46, 3497-3502.

Ioku, K., Aoyama, Y., Tokuno, A., Terao, J., Nakatani, N. and Takei, Y. (2001). Various cooking methods and the flavonoid content in onion. J. Nutr. Sci. Vitaminol., 47, 78-83.

Makris, D.P. and Rossiter, J.T. (2001). Domestic Processing of onion bulbs (Allium cepa) and asparagus spears (Asparagus officinalis): Effect of flavonol content and antioxidant status. J. Agric. Food Chem., 49, 3216-3222.

Mizoi, M., Sawayama, S., Kawabata, A. and Seiichi, H. (1992). Browning reaction of onion by heating. Nippon Eiyo Shokuryo Gakkaishi, 45, 441-447 (in Japanese).

Tamaki, M. and Ukai, M. (2003). Changes in the taste, flavor, free sugar, and browning of onion (Allium cepa L.) during long-term frying. Nihon Kasei Gakkaishi, 54, 69-76 (in Japanese).

Tamaki, M., Ukai, M. and Homma, S. (1996). Gel chromatography of browned compounds in heated onion. Nippon Shokuhin Kagaku Kogaku Kaishi, 43, 1293-1298 (in Japanese).

Tsushida, T. and Suzuki, M. (1996). Flavonoid in fruit and vegetables, 2: Content of flavonol glucosides and some properties of enzymes metabolizing the glucosides in onion. Nippon Shokuhin Kagaku Kougaku Kaishi, 43, 642-649 (in Japanese).

Yan, X., Suzuki, M., Ohnishi-Kameyama, M., Sada, Y., Nakanishi, T. and Nagata, T. (1999). Extraction and identification of antioxidants in the roots of yacon (Smallanthus sonchifolius). J. Agric. Food Chem., 47, 4711-4713. 